IZA DP No. 10327

Origins and Implications of Family Structure across Italian Provinces in Historical Perspective

Graziella Bertocchi

Monica Bozzano

October 2016 


\title{
Origins and Implications of Family Structure across Italian Provinces in Historical Perspective
}

\author{
Graziella Bertocchi \\ University of Modena and Reggio Emilia, \\ CEPR, DGI and IZA \\ Monica Bozzano \\ University of Modena and Reggio Emilia
}

Discussion Paper No. 10327

October 2016

\author{
IZA \\ P.O. Box 7240 \\ 53072 Bonn \\ Germany \\ Phone: +49-228-3894-0 \\ Fax: +49-228-3894-180 \\ E-mail: iza@iza.org
}

Any opinions expressed here are those of the author(s) and not those of IZA. Research published in this series may include views on policy, but the institute itself takes no institutional policy positions. The IZA research network is committed to the IZA Guiding Principles of Research Integrity.

The Institute for the Study of Labor (IZA) in Bonn is a local and virtual international research center and a place of communication between science, politics and business. IZA is an independent nonprofit organization supported by Deutsche Post Foundation. The center is associated with the University of Bonn and offers a stimulating research environment through its international network, workshops and conferences, data service, project support, research visits and doctoral program. IZA engages in (i) original and internationally competitive research in all fields of labor economics, (ii) development of policy concepts, and (iii) dissemination of research results and concepts to the interested public.

IZA Discussion Papers often represent preliminary work and are circulated to encourage discussion. Citation of such a paper should account for its provisional character. A revised version may be available directly from the author. 


\section{ABSTRACT}

\section{Origins and Implications of Family Structure across Italian Provinces in Historical Perspective*}

In this study we review the literature on the origins and implications of family structure in historical perspective with a focus on Italian provinces. Furthermore we present newlycollected data on three of the main features of family structure: female mean age at marriage, the female celibacy rate, and the fraction of illegitimate births. The data are collected at the provincial level for 1871, the year of Italy's political unification. The analysis of the data allows us to confirm and quantify the geographic differentiation in family patterns across the country. We also illustrate the links between family structure and a set of socio-economic outcomes, in the short, medium, and long run.

JEL Classification: J12, N33, O1, Z1

Keywords: family structure, Italian provinces, institutions, culture, development

Corresponding author:

Graziella Bertocchi

Dipartimento di Economia Marco Biagi

University of Modena and Reggio Emilia

Viale Berengario 51

41121 Modena

Italy

E-mail: graziella.bertocchi@unimore.it

\footnotetext{
* This chapter has been prepared for the book "Cliometrics and the Family: Global Patterns and their Impact on Diverging Development" edited by Claude Diebolt, Auke Rijpma, Sarah Carmichael, Selin Dilli, and Charlotte Störmer. Generous financial support from Fondazione Cassa Risparmio di Modena and the Italian University Ministry is gratefully acknowledged.
} 


\section{Introduction}

The analysis of the family as a central socio-economic unit and main vehicle of socialization, and therefore of transmission of behavior and values, has recently become the focus of an expanding literature stressing the relevance of cultural factors for economic outcomes (Bisin and Verdier, 2000; Guiso et al., 2006). Parallel research within the Cliometrics literature has increasingly tried to find new sources and methods in order to measure the role of the family in historical perspective. Within this broad research line, this chapter intends to look at the Italian family structure, its origins, and its implications, over time from the Middle Age to the present day, across spatial geopolitical entities, both in theoretical terms and through newly-collected historical statistics.

This introductory section to the chapter provides a comprehensive but self-contained state of the art of the available research on family organization and its origins, drawing from the economic, demographic and sociological literatures and focusing on some relevant refinements which are needed to understand the Italian case.

Seminal research by Hajnal $(1965,1982)$ establishes the crucial role of the European Marriage Pattern (henceforth EMP), a family model diffused at least since the 16th century in Northern Europe, west of a line running from Trieste to St. Petersburg. According to Hajnal, the EMP was characterized by nuclear residential patterns, relatively late marriage for both sexes but particularly for women, and widespread permanent female celibacy. In Hajnal's interpretation these features are closely connected: marriage could have occurred at an early age only under the protection of a complex family model, since the nuclear model would not have created the economic conditions permitting the formation of an independent household at an early age. ${ }^{1}$ Complementary characteristics of the EMP were also the pervasive presence of servants living within the household and, as pointed out by Laslett (1977), a low age gap between spouses. The pattern prevailing in Southern Europe, again according to Hajnal, was instead characterized by early marriage and complex families, thus departing radically from the EMP.

At a subsequent stage, in his analysis of family organization in Europe since the Middle Age, Todd (1990) develops a classification of family types organized along two axes. The first axis reflects the relationship between parents and children as captured by residential habits: families can be classified as liberal or authoritarian. They are classified as liberal when they are based on the nuclear model and children establish their own separate household after marrying, while they are classified as authoritarian when they follow the extended pattern and different generations live together. The second axis in Todd's classification focuses on the relationship between siblings as captured by inheritance rules: such rules can be classified as equal or unequal. Equal inheritance rules imply partition of family wealth among all children, while unequal rules can take the form of primogeniture, unigeniture, or discretion, that is the absence of formal rules. The combination of the two axes generates four family types: the absolute nuclear family (liberal and unequal), the

\footnotetext{
${ }^{1}$ In the demographic literature, delayed marriage and high celibacy are also referred to as "Malthusian preventive checks" of fertility, that is behaviors aimed at controlling reproduction, consciously or not, which differ from the "positive checks", namely mortality by famine, wars, or diseases (Malthus, 1798).
} 
egalitarian nuclear family (liberal and equal), the stem family (authoritarian and unequal); and the communitarian family (authoritarian and equal). ${ }^{2}$

Relative to Hajnal, Todd therefore questions the association between co-residence and late marriage, suggesting in particular that the complementarity between nuclear residential rules and late marriage is not robust. For instance, Southern Europe witnessed both early female marriage within nuclear families as well as late female marriage age within complex ones. Dennison and Ogilvie (2014) present a meta-study which confirms that the EMP did not uniformly prevail throughout Europe and that its two distinctive components did not always coincide.

Within the research line on family patterns the case of Italy stands out for its complexity, which cannot be completely captured by the aforementioned classification approaches. In contrast with North-Western Europe the family model prevailing in Italy and the rest of Southern Europe appears to be characterized by early marriage and complex families. Laslett and Wall (1972) suggest early on the presence of a 'Mediterranean' model based on the extended family across Southern Europe. This view is supported by research by Herlihy and Klapisch-Zuber (1978) based on the Tuscan 'catasto', showing for this region a prevalence of extended families, early female marriage age, and low female celibacy, with a negligible presence of servants. The predominance of this pattern can be justified by the diffusion of the sharecropping system and also by non-economic factors having to do with the culture of female honor, in relation to female sexuality, and 'amoral familism' (for the latter, see Banfield, 1958). The 'Mediterranean' model is later recognized by Hajnal (1982) and Laslett (1983) themselves.

However, the assumption that the findings for Tuscany can be extended to the entire peninsula is quickly questioned by subsequent research and new data collection covering different areas of the country (for a summary, see Viazzo, 2003, and Curtis, 2014). For instance, Silverman (1968, 1975) establishes the diffusion in the South of the nuclear model, characterized by simple conjugal households with early marriage age, especially for women. Similar conclusions are drawn by Barbagli $(1987,1991)$ and Del Panta et al. (1996). At the same time, investigations by Kertzer and Brettell (1987) and Kertzer and Hogan (1991) shed new light on the presence of late female marriage age in combination with the extended family model in Northern and Central Italy. Both combinations are in conflict with the hypotheses behind the EMP, and open the way for a new approach to the analysis of the Italian case, pointing to heterogeneity and diversity rather than to the quest of a uniform model. This new approach is capable of accommodating the presence of complex and extended families with late marriage in the North and Center together with the presence of nuclear families with early marriage in the South, yet with further exceptions in more delimited areas of the country. For instance, Sardinia departs from the rest of the South by showing a combination of neo-locality with late marriage for both women and men, while the Alps in the North show mixed features (Viazzo, 2003).

\footnotetext{
2 Todd obtains his classification by applying the "regressive method" due to Bloch (1949). Starting with contemporaneous census data for Western Europe, mostly collected for the 1950s and 1960s, he goes back to historical data. By comparison he can establish strong persistence of the observed family types back to the Middle Age.
} 
Barbagli (1987) also highlights further dimensions of variability, across cities vs. rural areas with complex families being more diffused in the latter, and across social classes with the patrilinear model more frequent among the wealthier, not to mention the time evolution of the patterns being observed.

The belief that Italy is better described within a regional, or sub-regional approach is now widely agreed upon by economists as well as historians, sociologists, and anthropologists. However, while the initial data collection effort was focused on delimited areas, scattered around what is currently the Italian territory, with the aid of never-exploited data from the national census and other sources it is now possible to systematize the analysis of family structure on the basis of a province-level dataset covering its multiple features. The main goal of this chapter is to present this dataset, combining information taken from Bertocchi and Bozzano (2015) with newly-collected data at the provincial level of disaggregation on the three main features defining the EMP, as highlighted by the literature: female age at marriage, female celibacy rate, and illegitimacy rate. While a fullyfledged empirical investigation based on such data is beyond our scope, we also aim to provide the initial groundwork to understand the implications of each feature of family structure, through an analysis of its correlation with a set of economic and social indicators, measured both for the first decade after the political unification of the country and for present-day Italy.

The rest of the chapter is organized as follows. The second, and core, section provides the new province-level evidence on crucial indicators of family structure, building on Bertocchi and Bozzano (2015). The third section analyzes the correlation between the multiple features of family structure uncovered in the second section and economic development, human capital accumulation, gender outcomes, and fertility both in a short-to-medium run and in a long-run perspective. The fourth and last section summarizes our results and suggests ideas for further research.

\section{The Italian family pattern: A province-level dataset}

The main contribution of this chapter is to organize the discussion on the characteristics of the Italian family structure and marriage patterns, starting from the compilation of a systematic, province-level dataset covering the whole country and at the same time accounting for the large degree of variability highlighted by previous contributions.

We start by summarizing the province-level analysis of Italian family types based on Todd (1990) and adapted by Bertocchi and Bozzano (2015). We then extend and complement this information with newly-collected data covering three specific dimensions which have been recognized as crucial for the analysis of family structure and the debate on the diffusion of the EMP: female mean age at marriage, women celibacy, and illegitimate births.

Our data cover 69 Italian provinces in 1871, the year that marks the completion of the Unification of the country, with the addition of Rome, Mantua, and the provinces belonging to Veneto ${ }^{3}$ to the territories that had already been included in the Kingdom of Italy since 1861. The source of the data is the census (MAIC, 1872).

\footnotetext{
${ }^{3}$ The latter are Belluno, Padua, Rovigo, Treviso, Udine, Venice, Verona, and Vicenza.
} 


\subsection{Family types}

In order to describe family structure across Italian provinces, we employ two variables. The first captures the diffusion of the nuclear household, as opposed to the complex one. The second defines multiple types of family structure taking into account not only the presence of neo-locality but also other features such as inheritance rules and female age at marriage.

The first indicator is based on the classification of residential habits provided by Todd (1990), who distinguishes between nuclear (with neo-local residence after marriage) and complex (or stem, extended, or communitarian) families. This classification is meant to capture the relationship between parents and children. On this basis nuclear families where children leave after marriage can be viewed as liberal, while complex families where different generations live together can be viewed as authoritarian. Following Duranton et al. (2009), it is possible to match the information in Todd (1990) with 69 Italian province-level geographic units (at 1871 borders). Using a dummy variable that takes value 1 if the nuclear family pattern is prevailing in the province and 0 otherwise, Bertocchi and Bozzano (2015) show that the nuclear family model prevails in nearly 54 percent of the provinces, as reported in Table A1 in the Appendix.

Figure 1 presents the geographical distribution of the provinces according to the nuclearity dimension of family structure. Provinces are identified by abbreviations of current provincial names. ${ }^{4}$ The figure shows that the nuclear family prevails both in the North-West and in the South, while complex household are the norm in the North-East and the Center.

Figure 1. Nuclear vs. complex families

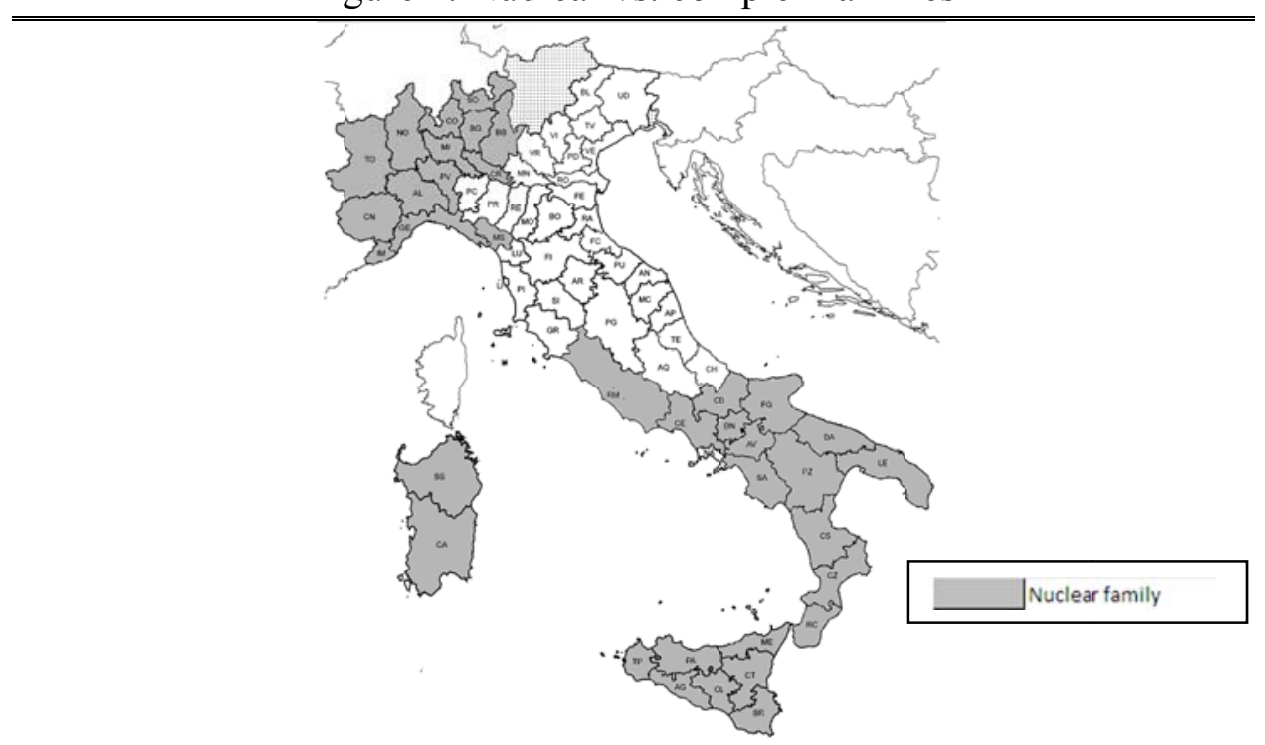

Provinces are identified by abbreviations of current provincial names. See the Appendix for sources.

The second indicator is based on the Todd (1990) four-way classification which combines the residential habits dimension with a second dimension reflecting rules of inheritance. The additional dimension mirrors the relationship between siblings which indeed can be captured by inheritance

\footnotetext{
${ }^{4}$ All maps display a dotted area in the North corresponding to Trentino, which was not part of the Kingdom of Italy in 1871 but entered afterwards. See the Appendix for definitions and sources of variables.
} 
rules. Accordingly, family wealth can be allocated through equal and unequal ways. Partible inheritance represents the former, while primogeniture, unigeniture, or the absence of formal rules represent variations of the latter. In terms of rules of inheritance, Italian provinces are characterized by rather limited variability if compared to residential habits, with unequal partition, usually in the form of primogeniture, prevailing only in Veneto, that is in only 13 percent of the provinces.

The combined classification based on residential habits and inheritance rules generates four family types: the absolute nuclear family (characterized by the absence of formal inheritance rules apply), the egalitarian nuclear family, the stem family, and the communitarian family. Todd also acknowledges the presence of a fifth type, the incomplete stem family, which is authoritarian and de facto unequal despite the de jure presence of egalitarian inheritance rules. This fifth type appears to be particularly common in areas located near national borders. ${ }^{5}$

The Todd classification is adapted for Italian provinces by Bertocchi and Bozzano (2015) as follows. First, they show that only three of the Todd family types are relevant for Italy, since the absolute nuclear family is never represented. Second, they confirm that in Italy the stem family only appears in its incomplete version, at the border with the Austrian Empire. Finally, they augment the Todd classification in order to distinguish between two different versions of the egalitarian nuclear family, based on late vs. early female marriage age. Information on the areas exhibiting either tendency is taken from Del Panta et al. (1996). As a result, Bertocchi and Bozzano (2015) obtain for Italy four family types: egalitarian nuclear with late marriage, incomplete stem, communitarian, and egalitarian nuclear with early marriage. This classification generates a set of four dummy variables which allows to draw the map presented in Figure 2.

Figure 2 illustrates the geographical distribution of the four family types based on the adaptation of the Todd (1990) classification proposed by Bertocchi and Bozzano (2015). The figure shows that the egalitarian family with late female marriage age prevails in the North-West and Sardinia, while the incomplete stem characterizes the North-East. The communitarian model in turn is the norm in the Center, and the egalitarian one with early female marriage age in the rest of the South. Overall, the figure shows a large degree of variability but at the same time allows to identify relatively homogeneous areas, even it is worth stressing that differentiated customs - other than the prevalent ones - may still be represented within each province. ${ }^{6}$

\footnotetext{
${ }^{5}$ Todd (1984) also proposes an alternative classification criterion based on the relationship between husband and wife as captured by the degree of feminism, which is maximum under matrilinearity, minimum under patrilinearity, and intermediate under bilaterality. A family system is considered matrilinear if it assigns a prominent social role to the kinship of the wife.

${ }^{6}$ Italy exhibits rich variation in family types also in an international comparison. For instance, Spain exhibits only two family types: the stem in the North and the egalitarian nuclear in the South, while England presents the egalitarian nuclear family in the East and the incomplete stem in the West.
} 


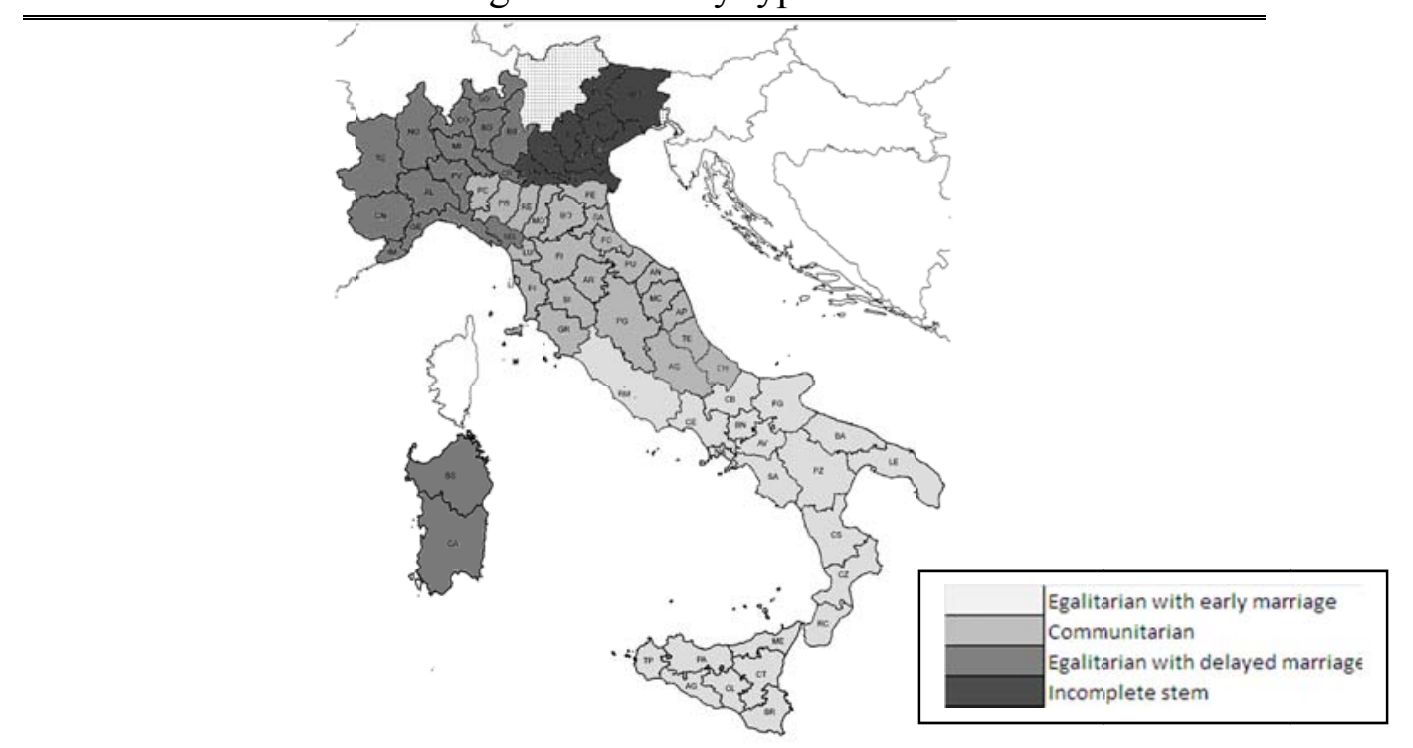

Provinces are identified by abbreviations of current provincial names. See the Appendix for sources.

\subsection{Female age at marriage}

The 1871 census reports province-level information on the age at marriage for both spouses, for all marriages taking place in that year (MAIC, 1872, vol. 2). Each spouse's age is provided by classes (below 20, 20-24, 25-29, 30-44, 45-59, and over 60). Raw data show for each province a relatively high mean age for females, always above age 23, where age 23 is indicated by Hajnal $(1965,1982)$ as a threshold to define late marriage age. ${ }^{7}$ However, since raw data include second marriages, we focus on an alternative indicator by disregarding marriages where the bride is older than 45 , so as to presumably exclude second marriages of former widows. Summary statistics are presented in Table A1 in the Appendix. Using the adjusted measure, that ranges from age 22 to almost 28, we find that mean age at marriage is lowest, at about 22, in Sicily (in particular, in the provinces of Siracusa, Caltanissetta, and Girgenti - currently Agrigento), which is consistent with previous findings reporting low female age at marriage in the South. Marriage age is higher in the North, but there are some noticeable exceptions. In fact, surprisingly, the province of Alessandria in Piedmont also shows an equally low age of 22 as Sicily, despite the fact that it lies in the area characterized by the nuclear family with delayed marriage. On the other hand of the spectrum, female age at marriage is especially late, at over 26, both in some Central provinces (Ascoli Piceno, Teramo) and Sardinia (Cagliari). The latter finding is consistent with Viazzo (2003). ${ }^{8}$

Figure 3 provides a visualization of the data, with the geographic distribution by quartiles of female age at marriage in 1871. The darker the shade of the provincial surface, the higher is female mean age at marriage. As anticipated, the map shows a large degree of variability along this dimension,

\footnotetext{
${ }^{7}$ The threshold for late age at marriage is not uniquely defined in the literature. For example, Carmichael et al. (2011) set it at 24 for women and 27 for men whereas Dennison and Ogilvie (2014) at 23-24 years of age for women.

${ }^{8}$ Data on male mean age at marriage (again adjusted to exclude marriages where the bride is older than 45) reveal that the relevant range for men is between 27 and 32, with a limited age difference between grooms and brides ranging from 2 to 5 .
} 
with the highest age quartile being more common in the Center but also in some peripheral provinces located both in the North (Sondrio and Udine) and South (Lecce). The lowest quartile includes most of Sicily, other Southern provinces such as Potenza, Foggia, and Campobasso, and an extended cluster of provinces in the North-West formed by Cuneo, Alessandria, Pavia, and Genoa.

Figure 3. Female age at marriage, 1871

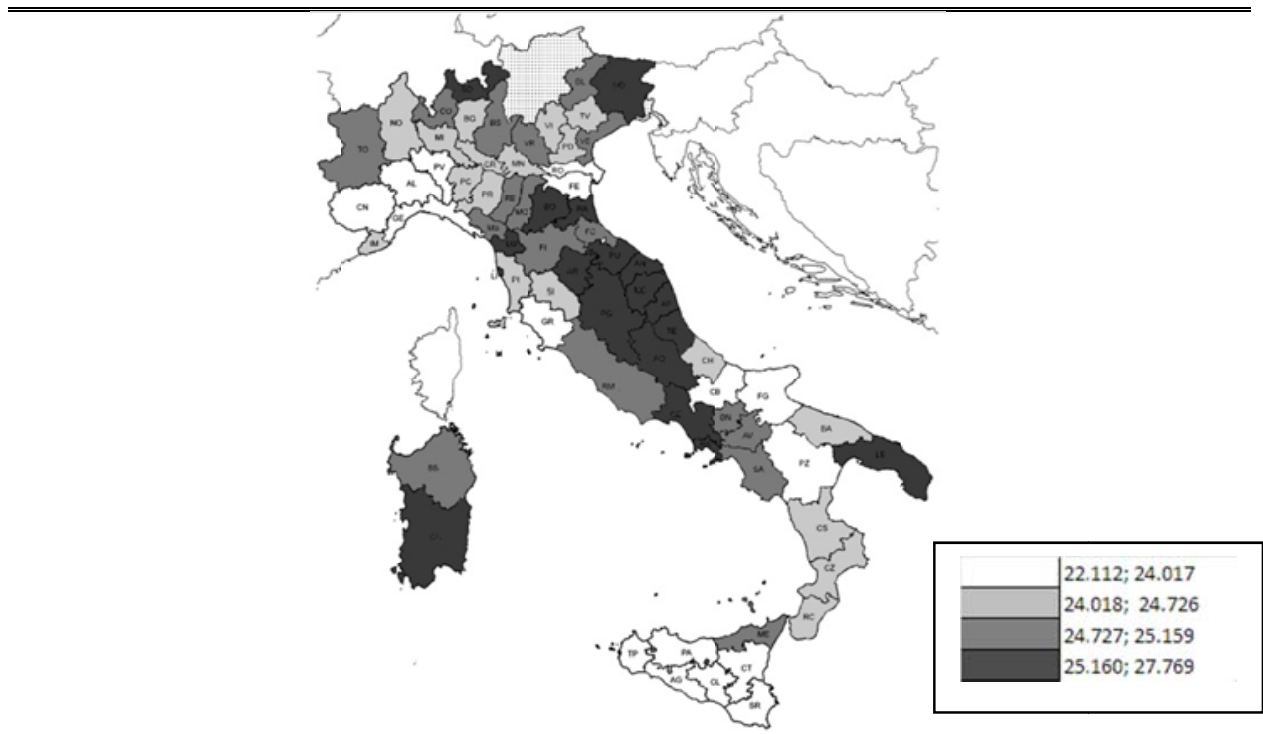

The darker the shade, the higher is female mean age at marriage in the province. Provinces are identified by abbreviations of current provincial names. See the Appendix for sources.

From a different albeit related perspective, further information can be extracted from the share of brides younger than 20 (computed as the number of brides aged 20 or less over the total number of marriages). Such share ranges from over 2 percent in the Central province of Macerata to 40 percent in the Sicilian province of Girgenti (see Table A1). It generally tends to be higher in the Southern areas where female mean age at marriage is low, and lower in the Center-North, again with the noticeable exception of Alessandria reaching almost 30 percent.

Figure 4 displays the geographic distribution by quartiles of the share of brides younger than 20 in 1871. The darker the shade of the provincial surface, the lower is the share. Being this variable highly correlated with female mean age at marriage, the map displays a very similar pattern if compared with that in Figure 3, with a large area characterized by a small fraction of young brides localized in the Center of the country. ${ }^{9}$

Overall, the information we collected on female marriage age highlight that a common general pattern can hardly be detected for the whole country and that wide territorial differentials exist also between contiguous territories.

\footnotetext{
${ }^{9}$ To account for female age at marriage, Bertocchi and Bozzano (2015) propose an alternative measure based on data from Barbagli (1987) on the percentage of women married below the age of 15 in 1872-75. The original source is DIRSTAT (1877). However, information is available only at the regional level. Consistent with the variables presented here, on average women marry before age 15 years in only 3 percent of the regions, even though the figure is as high as 13 percent in the case of Sicily.
} 


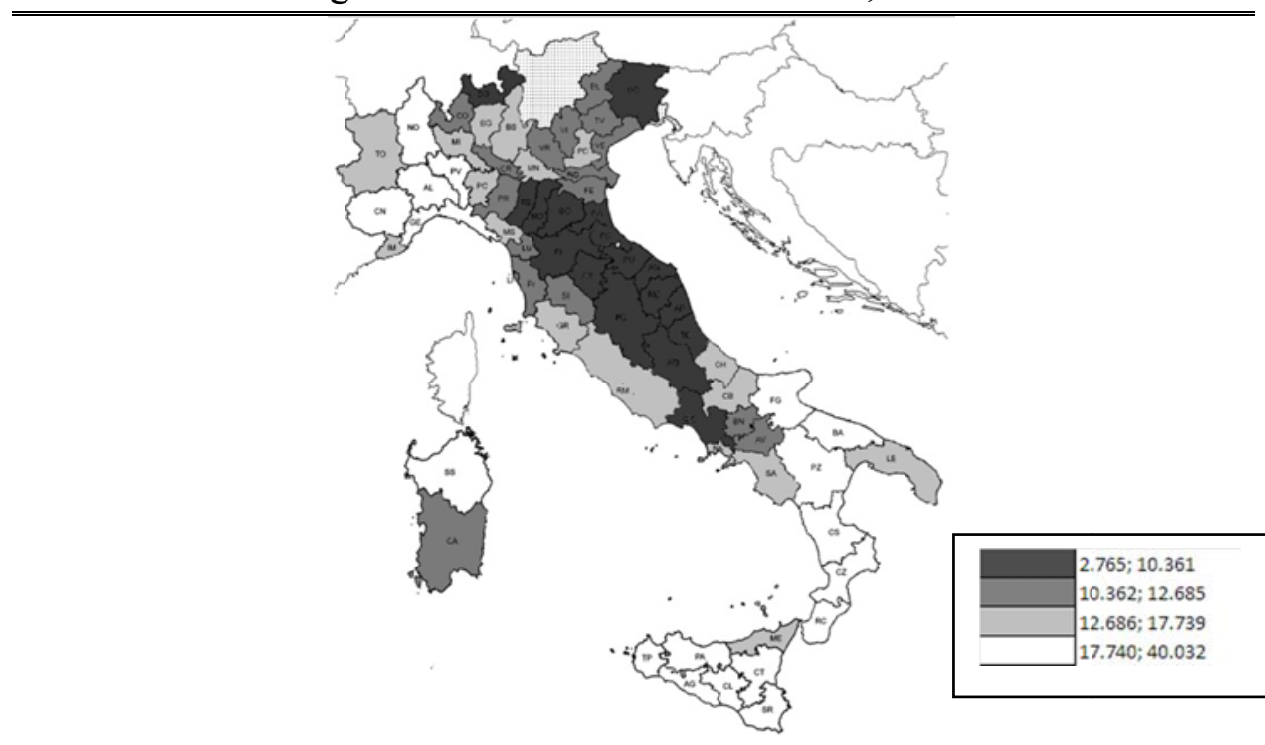

The darker the shade, the lower is the share of brides under 20 in the province. Provinces are identified by abbreviations of current provincial names. See the Appendix for sources.

\subsection{Female celibacy}

Since high celibacy rates are one of the characterizing features of the EMP, in the effort to illustrate how Italy fares in this dimension we also report provincial data about celibacy, in particular for women. Consistent with the demography literature, we define the female celibacy rate as the fraction of women above age 50 who never married (widows are therefore not counted). Information is made available by the 1871 census (MAIC, 1872) for each single age group, by year. We define our variable as the sum of all women of age 50 and more, divided by the female population older than 50. Since census data do not provide information on subsequent marriages, our definition cannot capture definitive celibacy, even though the probability that a woman marries for the first time after age 50 is very low. ${ }^{10}$

According to Hajnal $(1965,1982)$, celibacy rates can be considered as high when they are above 10 percent. ${ }^{11}$ Table A1 reports that across Italian provinces our variable ranges from about 4 (Rovigo) to 17 percent (Naples, Reggio Calabria). To be noticed is that most areas, particularly in the Po Valley and in those provinces situated in the area of Tuscany, show a low female celibacy rate irrespective of the prevailing household structure. Indeed, while high celibacy should be associated with a higher level of economic development and an advanced stage of the demographic transition, celibacy remains limited in many Northern provinces, both in the East (Rovigo, Treviso, Padua) and the West (Pavia, Alessandria, Mantua).

Figure 5 illustrates the geographic distribution by quartiles of the female celibacy rate in 1871 . The darker the shade of the provincial surface, the higher is the rate. Once again, the picture reveals substantial heterogeneity across provinces, with the highest levels of celibacy spread around some Northern and Southern provinces. On the other hand, female celibacy is at its lowest around the Po

\footnotetext{
${ }^{10}$ As an alternative measure, Livi Bacci (1980) employs the celibacy rate for women between age 50 and 54.

11 More recently Voiglander and Voth (2013) specify that high celibacy rates range between 10 and 30 percent depending on time and place.
} 
Valley and Sardinia. The newly-collected data confirm that in 1871 Italy displays a broad area of low celibacy rates in those provinces located in the Po Valley which were also characterized by high nuptiality rates according to Livi Bacci (1980). Again a consistent picture does not emerge for Italy as a whole and no general pattern can be detected even at lower levels of aggregation, namely at the regional one.

Figure 5. Female celibacy rate over 50, 1871

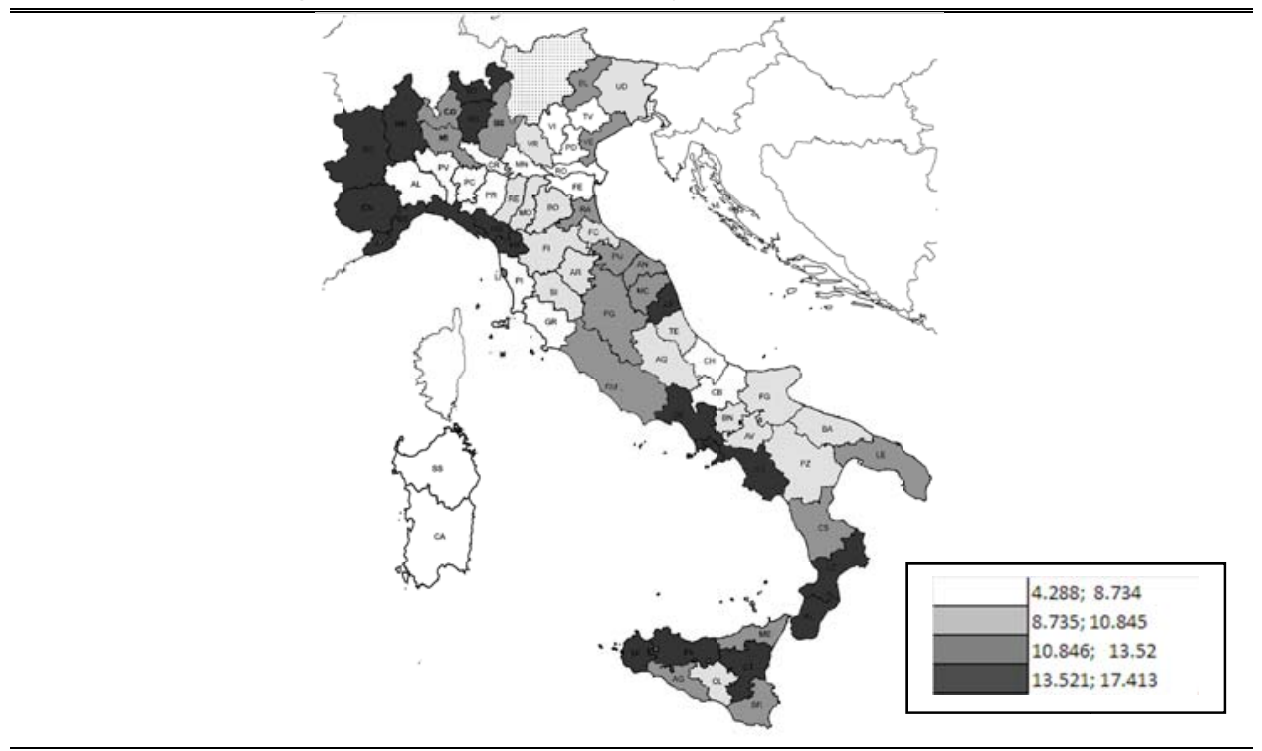

The darker the shade, the higher is the female celibacy rate in the province. Provinces are identified by abbreviations of current provincial names. See the Appendix for sources.

\subsection{Illegitimate births}

A third important indicator of family patterns is the fraction of illegitimate births. In fact, the assumptions behind the EMP, in addition to late and non-universal marriage, also include a strong restrictive pressure on fertility, which becomes stronger when coupled with wery low levels of outof-wedlock childbirths. To take account of this dimension within Italian boundaries, we obtain data on illegitimate births from life statistics in 1871 (MAIC, 1874). Since 1871 data are not available for Rome, ${ }^{12}$ for this province we employ 1872 data (MAIC, 1875). The illegitimacy rate is calculated taking into account both out-of-wedlock births and abandoned infants over the total number of births in the same year.

Overall, Italy displays on average an illegitimacy rate of about 7 per one hundred births in 1871, with a wide variability across different provinces, from 1.5 in Treviso, in the North-East, to over 17 in Pesaro-Urbino in the Center (see Table A1). If we take as a benchmark a rate between 8 and 10 percent, we find that the illegitimacy rate at Unification is still high in several areas.

Figure 6 illustrates the geographic distribution by quartiles of the illegitimate rate in 1871 . The darker the shade of the provincial surface, the lower is the rate. The map reveals that a large portion of the country, including parts of the North and several provinces in the continental South of the

\footnotetext{
${ }^{12}$ Rome entered the unified Kingdom of Italy in 1871 but the datum is missing for this year in MAIC (1874).
} 
peninsula (in particular Avellino, Benevento, and Campobasso), is associated with very low to low fractions of out-of-wedlock births. On the other hand, provinces with high levels of illegitimacy are concentrated in the Center and in the South of the country.

Again these never-exploited data do not show any coherent picture, since the prevailing socioeconomic and demographic conditions which lead to high illegitimacy rates vary across family types and other features of the EMP. In fact one would expect to observe higher illegitimacy rates in provinces where marriage is delayed and complex households prevail: this actually happens in a few provinces in the Center of Italy, but high illegitimate rates are also found in Southern provinces which, as previously shown, are mostly characterized by early marriage, with a large share of brides marrying in their teens, as well as by the nuclear structure of the household.

Figure 6. Illegitimacy rate, 1871

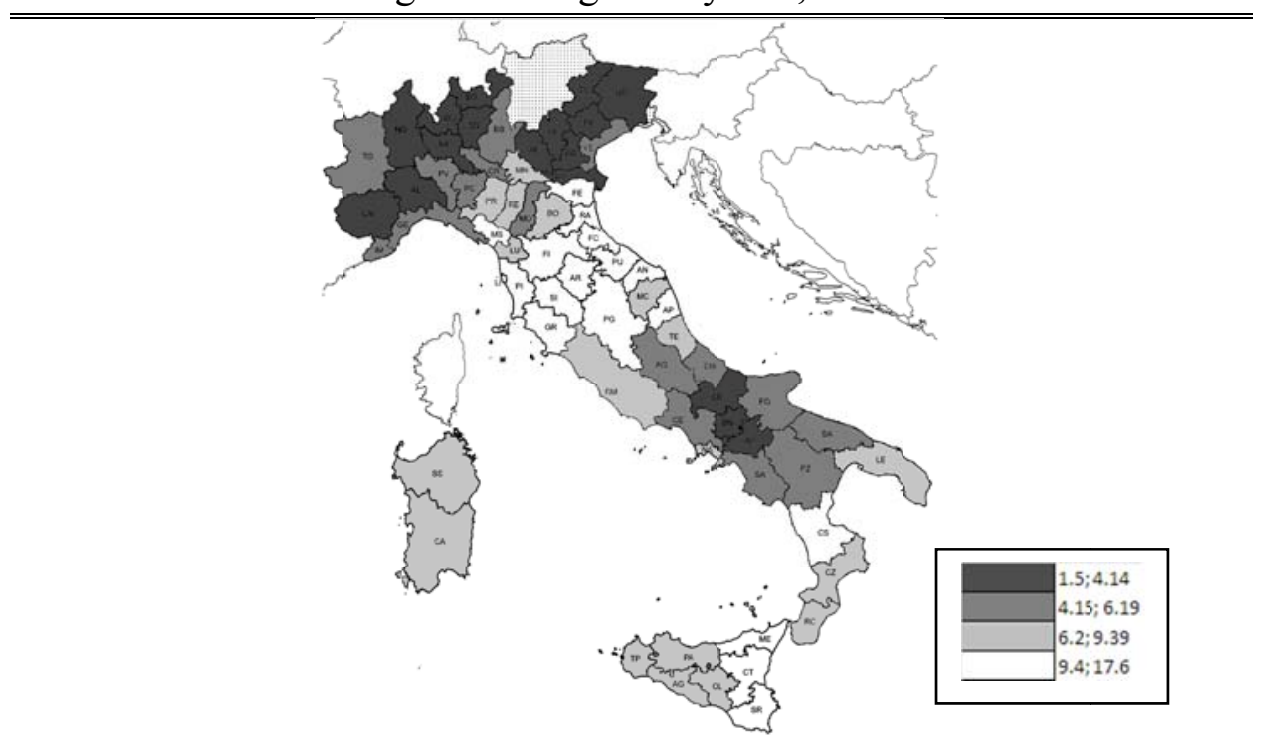

The darker the shade, the lower is the illegitimacy rate in the province. Provinces are identified by abbreviations of current provincial names. See the Appendix for sources.

\subsection{The multiplicity of Italian family patterns}

While the newly-collected data already allow us to deepen our understanding of the multiple dimensions defining family structure across Italian provinces, further insights can be gained by examining the correlations between each indicator, as provided in Table 1.

Table 1: Correlation among variables reflecting family structure

\begin{tabular}{|c|c|c|c|c|c|}
\hline & $\begin{array}{c}\text { Female age at } \\
\text { marriage }\end{array}$ & $\begin{array}{c}\text { Share of } \\
\text { brides under } \\
20\end{array}$ & $\begin{array}{c}\text { Female } \\
\text { celibacy rate }\end{array}$ & $\begin{array}{c}\text { Illegitimacy } \\
\text { rate }\end{array}$ & $\begin{array}{l}\text { Nuclear } \\
\text { families }\end{array}$ \\
\hline Female age at marriage & 1 & & & & \\
\hline Share of brides under 20 & $-0.8325^{*}$ & 1 & & & \\
\hline Female celibacy rate & 0.2159 & 0.0734 & 1 & & \\
\hline Illegitimacy rate & $0.2557^{*}$ & -0.1113 & 0.1235 & 1 & \\
\hline Nuclear families & $-0.4111^{*}$ & $0.5947^{*}$ & $0.3822 *$ & $-0.3137 *$ & 1 \\
\hline
\end{tabular}

* indicates significance at $5 \%$. 
Starting with female mean age at marriage, as expected we find it is significantly and negatively correlated with the share of brides below age 20. More interestingly, female marriage age is negatively correlated with the presence of the nuclear family, which is driven by the diffusion of the latter in the South but also by the position of certain Northern provinces. Even though for simplicity Table 1 does not report the four dummy variables identifying the Todd family types, marriage age turns out to be negatively correlated with the egalitarian nuclear family type with early marriage and positively correlated with the communitarian family type. An identical pattern, with an inverted sign of the relevant correlations, emerges for the share of brides younger than 20 .

Female celibacy is positively correlated only with nuclearity, while the illegitimacy rate is correlated positively with female mean age at marriage and negatively with nuclearity. Moreover, it is correlated positively with the communitarian family type and negatively with the incomplete stem family type. Summing up, nuclearity appears to be correlated with all the other dimensions: namely, it is associated significantly with a lower female age at marriage, a higher share of young brides, a higher celibacy rate, and a lower illegitimacy rate.

Overall, as uncovered by the aforementioned research and anticipated in the previous section, the hypotheses behind the EMP are strongly questioned in light of our findings. In fact, taking into consideration its main features - high female age at marriage, high celibacy rates for women, and low illegitimacy rates - no province in the Italian territory is able to comply with all three categories contemporarily. The notion of the EMP appears to overly generalize the specificities of the Italian demographic and marriage patterns, which are instead strongly characterized by multiple household formation models. On the other hand, the ability of the nuclearity dimension to capture at once different facets of family structure is confirmed by our analysis.

\section{Short- and long-run implications of family structure}

This third part of the chapter intends to contribute to the empirical literature which focuses on the measurement and estimation of the persistent effect of historical family organization and related mechanisms on current economic, political, and social developments, with particular attention to contemporary Italy. We are especially but not exclusively interested in the gender dimension.

Growing attention within the literature has been devoted to the long-term implications of the EMP. De Moor and van Zanden (2010) study its influence on women's position within the family, arguing that the practice of consensual marriage which was associated with the EMP led to a culture of gender equality with positive effects for female labor force participation and economic development. Foreman-Peck (2011) emphasizes the implications of a higher marriage age for human capital investment, particularly for women, while Voigtlander and Voth (2013) study the connection between the EMP and the Black Death, arguing that the latter triggered the shift toward the former by improving female employment prospects in the pastoral sector. Dennison and Ogilvie (2014) focus on the role played by the EMP in determining economic success and question the presence of a causal effect, while Carmichael et al. (2016) respond by arguing that the EMP restrained population growth by strengthening the position of women, through human capital 
accumulation and therefore economic growth. In more general terms, a persistent legacy of family structure and the dichotomy between extended and nuclear family types is separately studied by Greif (2006) with the aim to provide a theoretical explanation of the origins of the European corporation and the associated stimulus to economic growth, and by Greif and Tabellini (2015) in order to investigate differentials in the development patterns of China vs. Europe.

The classification of family types proposed by Todd (1990) has also been applied to the analysis of a number of issues. Duranton et al. (2009) find that the European regions characterized by egalitarian - rather than absolute - nuclear families show lower contemporaneous levels of female participation in the labor force. Dilli et al. (2015) apply Todd's classification to non-European parts of the world and highlight its influence on gender equality. Tur-Prats (2014) employs it for an analysis of domestic violence in Spain. Alesina and Giuliano $(2010,2014)$ introduce an alternative classification of family types based on a subjective variable obtained from survey data and measuring the strength of family ties. They find that this variable, which according to Galasso and Profeta (2010) is consistent with the one by Todd, is linked with lower female labor force participation and more traditional attitudes towards women.

More generally, a broader literature has highlighted the connection between family patterns, cultural traits, and their intergenerational transmission (Bisin and Verdier, 2000; Guiso et al., 2006). In particular, the relevance of cultural factors in explaining female outcomes has been investigated by Guiso et al. (2006) and Fernandez and Fogli (2009), while Alesina and Giuliano (2010) focus on the role of a specific trait of family culture represented by the strength of family ties.

Focusing on Italy, Bertocchi and Bozzano (2015) empirically investigate the influence of family types on the education gender gap during the period 1861-1901, taking into account economic, institutional, religious, and cultural correlates. They find that a higher female to male enrollment rate ratio in upper primary schools is associated with nuclear residential habits. Bertocchi and Bozzano (2016) explore the link between family culture and medieval commerce, a factor which is also associated with gendered human capital accumulation, and establish a positive and significant correlation between medieval commerce and the diffusion of the egalitarian family type with late marriage. Bozzano (2016) investigates the impact of family culture on present-day women's empowerment across Italian provinces and finds a strong and persistent effect of inherited family culture as measured by the prevailing fertility norms in the early twentieth century, as well as a significant association with the Todd family types. Indeed provinces with higher fertility rates in the past, which implied a more subordinated and caring role of women, are still characterized today by lower degrees of equality between sexes especially in top managerial positions. Moreover the communitarian family type is associated with higher gender equality in economic leadership whereas the egalitarian nuclear family with early marriage is the most gender unequal.

This section contributes to the above literature by identifying key significant correlations between our newly-collected indicators of family structure and a number of socio-economic. While a fullyfledged empirical investigation based on our data is presently beyond our scope, we aim to provide the initial groundwork to understand the implications of each feature of family structure both for the first decade after the political unification of the country and for present-day Italy. 
In Table 2 we summarize our results by reporting the sign of the significant correlations we found between five main dimensions of family structure and selected relevant indicators for 1871 and 1881. Variables definitions and sources are detailed in the Appendix. First of all, we investigate the association with variables proxying for economic development, since the literature has highlighted a positive impact of the EMP on economic success (on this debate see Dennison and Ogilvie, 2014, 2016, and Carmichael et al., 2016). To this scope, since data on income or wealth are not available for the period under consideration, as an indicator of the level of development we employ data on height taken from A'Hearn et al. (2009). This variable is negatively associated with the share of young brides and the presence of the nuclear family, both in 1871 and a decade later in 1881 . Second, we look at the correlation with the level of industrialization, measured by an index proposed by Ciccarelli and Fenoaltea (2013), which is positively associated with female celibacy, but only in 1871. To check the association with human capital accumulation as well as its gendered counterpart, we collect for each province data by gender on the literacy level of the adult population, i.e. people aged 20 or more (MAIC, 1872, 1883). We can then obtain a measure of the general literacy rate and the female to male ratio of the literacy rate, as a measure of gender equality in human capital accumulation. ${ }^{13}$ We find that, both in 1871 and 1881 , the former is negatively correlated with the illegitimacy rate, while the latter is negatively correlated with the share of young brides. This suggests that a more subordinated role of women is associated with a larger share of women who marry at a very young age, a link which has already been acknowledged in the literature. Finally, we include in the analysis a measure of fertility by calculating the crude birth rate as the number of live births over 1,000 inhabitants (MAIC, 1874, 1882; for Rome, MAIC, 1875). In 1871 it is correlated negatively with female mean age at marriage and positively with the share of young brides. The same pattern is confirmed for 1881, with an added positive correlation with nuclearity. ${ }^{14}$

Overall our results show very feeble evidence that the different characteristics of the EMP are associated with economic development, human capital accumulation, or women's empowerment. Surprisingly, according to our data, no relevant correlations exist with height. Besides, at least up to 1871, higher female mean age at marriage is not linked to education acquisition as captured by higher literacy as argued in the previous literature (Foreman-Peck, 2011). Moreover, if we interpret the female to male ratio in literacy rates as a measure of gender equality in opportunities, we see that the assumptions behind the EMP are not even correlated with female empowerment (De Moor and van Zanden, 2010; Carmichael et al., 2016). Finally, our fertility measure is only inversely correlated with female age at marriage, since as expected younger women tend to be more fecund, while contrary to expectations it is not responsive to the other two features of the EMP. Taken

\footnotetext{
${ }^{13}$ Campa et al. (2011) employ a measure of the gender gap in literacy in 1911 as an instrument for gender culture, which is in turn shown to affect the present gender gap in employment.

${ }^{14}$ Turning to family types, height is correlated negatively with the presence of the egalitarian nuclear family type with early marriage and positively with that of the incomplete stem family type. Literacy is negatively correlated with the egalitarian nuclear family with early marriage and positively with the egalitarian nuclear family with late marriage. Female to male literacy is negatively linked to the egalitarian nuclear family with early marriage. The crude birth rate in 1871 is correlated positively with the incomplete stem family type and negatively with the communitarian family while the same variable in 1881 is positively correlated with the egalitarian nuclear family with early marriage and negatively with the communitarian family. These correlations are not reported in Table 2 for simplicity.
} 
together these findings cast doubts about the explanatory power of the categorizations of the EMP in explaining the Italian demographic reality.

Table 2: The short- and medium-term influence of family structure

\begin{tabular}{|c|c|c|c|c|c|}
\hline & $\begin{array}{c}\text { Female } \\
\text { age at } \\
\text { marriage } \\
\end{array}$ & $\begin{array}{c}\text { Share of } \\
\text { brides } \\
\text { under } 20 \\
\end{array}$ & $\begin{array}{c}\text { Female } \\
\text { celibacy } \\
\text { rate } \\
\end{array}$ & $\begin{array}{l}\text { Illegitimacy } \\
\text { rate }\end{array}$ & $\begin{array}{l}\text { Nuclear } \\
\text { families }\end{array}$ \\
\hline \multicolumn{6}{|l|}{1871} \\
\hline Height & & - & & & - \\
\hline Industrialization & & & + & & \\
\hline Literacy & & & & - & \\
\hline F-to-m Literacy & & - & & & \\
\hline Crude birth rate & - & + & & & \\
\hline \multicolumn{6}{|l|}{1881} \\
\hline Height & & - & & & - \\
\hline \multicolumn{6}{|l|}{ Industrialization } \\
\hline Literacy & & & & - & \\
\hline F-to-m Literacy & & - & & & \\
\hline Crude birth rate & - & + & & & + \\
\hline
\end{tabular}

Notes: only significant correlations at 5 percent are reported. See the Appendix for source.

In what follows we run the same exercise by looking at long-run correlations emerging between each dimension of family structure and selected 2001 indicators of economic development, gender outcomes in the labor market, education, and fertility. Table 3 summarizes our results. ${ }^{15}$ First, to test the potential long-run relationship with the level of development in 2001, we employ income per capita in each province (Istituto Tagliacarne, 2011): this variable is negatively correlated with the share of young brides and nuclearity.

Then we turn to variables capturing the degree of gender equality in the labor market: in particular, we look at the female to male ratio in labor force participation rates and in top managerial positions (ISTAT, 2009). Both variables range from 0 to 1 and therefore increase in gender equality. The former measure is correlated positively with female mean age at marriage and negatively with the share of brides under 20 and nuclearity. Similarly, our measure of gender equality in economic leadership grows with female mean marriage age and, additionally, the illegitimacy rate and declines with the share of young brides and nuclearity.

Next, we analyze measures of human capital accumulation, again in its gendered version. We define two variables. The first is the female to male secondary attainment ratio, measured as the ratio between females with at least a high-school diploma over female population over age 19 and males with at least a high-school diploma over male population over age 19. The second variable in analogously defined at the higher education level as the female to male tertiary attainment ratio, i.e., the ratio between females with a university degree over female population over age 19 and males with a university degree over male population over age 19 (ISTAT, 2009). As a result, we find no correlation between the former and any family structure indicator, while at the higher-education level our variable grows with female marriage age and with the illegitimacy rate.

\footnotetext{
${ }^{15}$ We refer to the Appendix for sources and further details on the variables included in this analysis.
} 
As a final indicator we include fertility, as captured by the number of children per woman in 2001 (ISTAT, 2009), which is positively correlated with the share of young brides, the female celibacy rate, and nuclearity. Once again, as for nineteenth-century indicators, the nuclear family type emerges as a consistent correlate of several dimensions of the socio-economic level of development.

Table 3: The long-term influence of family structure

\begin{tabular}{|c|c|c|c|c|c|}
\hline & $\begin{array}{c}\text { Female } \\
\text { age at } \\
\text { marriage }\end{array}$ & $\begin{array}{c}\text { Share of } \\
\text { brides } \\
\text { under } \\
20\end{array}$ & $\begin{array}{c}\text { Female } \\
\text { celibacy } \\
\text { rate }\end{array}$ & $\begin{array}{l}\text { Illegitimacy } \\
\text { rate }\end{array}$ & $\begin{array}{l}\text { Nuclear } \\
\text { families }\end{array}$ \\
\hline \multicolumn{6}{|l|}{2001} \\
\hline Income & & - & & & - \\
\hline $\begin{array}{l}\text { Female to male labor force } \\
\text { participation ratio }\end{array}$ & + & - & & & - \\
\hline $\begin{array}{l}\text { Female to male ratio economic } \\
\text { leadership }\end{array}$ & + & - & & + & - \\
\hline \multicolumn{6}{|l|}{$\begin{array}{l}\text { Female to male secondary } \\
\text { attainment ratio }\end{array}$} \\
\hline $\begin{array}{l}\text { Female to male tertiary } \\
\text { attainment ratio }\end{array}$ & + & & & + & \\
\hline Fertility rate & & + & + & & + \\
\hline
\end{tabular}

Notes: only significant correlations at 5 percent are reported. See the Appendix for sources.

To conclude, in line with the evidence presented by Bozzano (2016), our long-run implications of the historically-determined marriage patterns across Italian provinces appear to be related to the transmission of cultural norms in favor of more gender equality. Indeed gender roles are historically determined and might have path-dependent effects on current women's outcomes through cultural intergenerational transmission and are mainly attached to heritage and traditions (Bisin and Verdier, 2000; Guiso et al., 2006). Basically areas characterized in the past by lower female age at marriage, in particular before 20 years of age, are significantly associated with a less favorable position of women and higher gender inequality in the labor market, in economic leadership, and at the higher levels of education.

\section{Conclusion}

In this chapter we have reviewed the literature on the origins and implications of family structure with a focus on Italian provinces at the borders defined in 1871 with the political unification of the country. We have also presented newly-collected province-level data on three of the main features of family structure: female mean age at marriage, the female celibacy rate, and the fraction of illegitimate births. Our analysis of the data allows to quantify the degree of geographic diversity prevailing across the country, as highlighted by previous contributions based on data collected from delimited, scattered areas. Finally, we have also illustrated significant correlations between the features of family structure described by our province-level data and a set of socio-economic indicators including measures of economic development, human capital accumulation, gender gaps, 
and fertility, with reference both to the decade immediately following Unification and to the present day.

Further research could extend our investigation in at least three interrelated directions. First, the empirical influence of family structure should be investigated thoroughly, taking into account other correlates and the potential for reverse causation. Second, while our data confirm the diversity of family patterns across Italian provinces, the economic, cultural, and institutional determinants of such diversity have not yet been deeply and systematically identified. Third, the evolution of family structure from Unification in the nineteenth century to present-day Italy, and its recent, fast convergence toward a less heterogeneous model, also deserve further exploration.

\section{References}

A'Hearn, B., F. Peracchi and G. Vecchi (2009), Height and the Normal Distribution: Evidence from Italian Military Data, Demography 46, 1-25.

Alesina, A. F. and P. Giuliano (2014), Family Ties, in P. Aghion and S. Durlauf, eds., Handbook of Economic Growth, vol. 2, North Holland, Oxford, 177-215.

Alesina, A. F. and P. Giuliano (2010), The Power of the Family, Journal of Economic Growth 15, 93-125.

Banfield, E. (1958), The Moral Basis of a Backward Society, Free Press, New York.

Barbagli, M., (1991), Three Household Formation Systems in Eighteenth- and Nineteenth-century Italy, in D. Kertzer and R. Saller (eds.), The Family in Italy from the Antiquity to the Present, New Yale University Press, New Haven.

Barbagli, M. (1987), Sistemi di Formazione della Famiglia in Italia, Bollettino di Demografia Storica 2, 80-127.

Bertocchi, G. and M. Bozzano (2016), Women, Medieval Commerce, and the Education Gender Gap, Journal of Comparative Economics 44, 496-521.

Bertocchi, G. and M. Bozzano (2015), Family Structure and the Education Gender Gap: Evidence from Italian Provinces, CESifo Economic Studies 61, 263-300.

Bisin, A. and T. Verdier (2000), Beyond the Melting Pot: Cultural Transmission, Marriage, and the Evolution of Ethnic and Religious Traits, Quarterly Journal of Economics 115, 955-988.

Bloch, M. (1949), Apologie pour l'Histoire ou Métier d'Historien, Librairie Armand Colin, Paris.

Bozzano, M. (2016), On the Historical Roots of Women's Empowerment across Italian Provinces: Religion or Family Culture? European Journal of Political Economy, forthcoming. 
Carmichael, S., T. De Moor and J. L. van Zanden (2011), Introduction, History of the Family 16, 309-311.

Carmichael, S. G., A. De Pleijt, J. L. van Zanden and T. De Moor (2016), The European Marriage Pattern and Its Measurement, Journal of Economic History 76, 196-204.

Ciccarelli, C. and S. Fenoaltea (2013), Through the Magnifying Glass: Provincial Aspects of Industrial Growth in Post-Unification Italy, Economic History Review 66, 57-85.

Curtis, D. R. (2014), The EMP in Pre-industrial Italy: Some Notes, mimeo, Leiden University.

Del Panta, L., M. Livi Bacci, G. Pinto and E. Sonnino (1996), La Popolazione Italiana dal Medioevo a Oggi, Laterza, Rome.

De Moor, T. and J. L. van Zanden (2010), Girlpower: The European Marriage Pattern and Labour Markets in the North Sea Region in the Late Medieval and Early Modern Period, Economic History Review 63, 1-33.

Dennison, T. and S. Ogilvie (2016), Institutions, Demography, and Economic Growth, Journal of Economic History 76, 215-217.

Dennison, T. and S. Ogilvie (2014), Does the European Marriage Pattern Explain Economic Growth? Journal of Economic History 74, 651-693.

Dilli, S., A. Rijpma and S. Carmichael (2015), Achieving Gender Equality: Development versus Historical Legacies, CESifo Economic Studies 61, 301-334.

DIRSTAT (1877), Popolazione. Movimento dello Stato Civile. Anno 1875, Tipografia Cenniniana, Rome.

Duranton, G., A. Rodriguez-Pose and R. Sandall (2009), Family Types and the Persistence of Regional Disparities in Europe, Economic Geography 85, 23-47.

Foreman-Peck, J. (2011), The Western European Marriage Pattern and Economic Development, Explorations in Economic History 48, 292-309.

Galasso, V. and P. Profeta, (2011), When the State Mirrors the Family: The Design of Pension Systems, CEPR Discussion Paper No. 8723.

Greif, A. (2006), Family Structure, Institutions, and Growth: The Origins and Implications of Western Corporations, American Economic Review 96, 308-312.

Greif, A. and G. Tabellini (2015), The Clan and the City: Sustaining Cooperation in China and Europe, CESifo Working Paper No. 5233. 
Guiso, L., P. Sapienza and L. Zingales (2006), Does Culture Affect Economic Outcomes? Journal of Economic Perspectives 20, 23-48.

Hajnal, J. (1965), European Marriage Patterns in Perspective, in D. V. Glass and D. E. C. Eversley (eds.), Population in History: Essays in Historical Demography, Edward Arnold, London, 101-143.

Hajnal, J. (1982), Two Kinds of Preindustrial Household Formation System, Population and Development Review 8, 449-494.

Herlihy, D. and C. Klapisch-Zuber (1978), Les Toscans et Leurs Familles. Une Etude du Catasto Florentin de 1427, Editions de l'Ecole des Hautes Etudes en Sciences Sociales, Paris.

Kertzer, D. and C. Brettell (1987), Advances in Italian and Iberian Family History, Journal of Family History 12, 87-120.

Kertzer, D. and D. Hogan (1991), Reflections on the European Marriage Pattern: Sharecropping and Proletarianisation in Casalecchio, Italy, 1861-1921, Journal of Family History 16, 31-45.

ISTAT (2009), Atlante Statistico dei Comuni. Settore Ambiente e Territorio, Istituto Nazionale di Statistica, Rome.

Istituto Guglielmo Tagliacarne (2011), Reddito e Occupazione nelle Province Italiane dal 1861 ad Oggi, Istituto Guglielmo Tagliacarne, Rome.

Laslett, P. (1983), Family and Household as Work Group and Kin Group: Areas of Traditional Europe Compared, in R. Wall, J. Robin and P. Laslett (eds.), Family Forms in Historic Europe, Cambridge University Press, Cambridge.

Laslett, P. and R. Wall (1972), Household and Family in Past Time, Cambridge University Press, Cambridge.

Livi Bacci, M. (1980), Donna, Fecondità e Figli, Il Mulino, Bologna.

MAIC (1883), Censimento della Popolazione del Regno d'Italia al 31 Dicembre 1881, Tipografia Bodoniana, Rome.

MAIC (1882), Statistica del Regno d'Italia. Popolazione. Movimento dello Stato Civile. Anno XX - 1881, Tipografia Bodoniana, Rome.

MAIC (1875), Statistica del Regno d'Italia. Popolazione. Movimento dello Stato Civile nell'Anno 1872, Stamperia Reale, Rome.

MAIC (1874), Statistica del Regno d'Italia. Popolazione. Movimento dello Stato Civile nell'Anno 1871, Stamperia Reale, Florence. 
MAIC (1872), Censimento della Popolazione del Regno d'Italia al 31 Dicembre 1871, Stamperia Reale, Rome.

Malthus, T. R. (1798), An Essay on the Principle of Population, J. Johnson, London.

Silverman, S. (1968), Agricultural Organization, Social Structure, and Values in Italy: Amoral Familism Reconsidered, American Anthropologist 70, 1-20.

Silverman, S. F. (1975), Three Bells of Civilization: The Life of an Italian Hill Town, Columbia University Press, New York.

Todd, E. (1984), L'Enfance du Monde, Structures Familiales et Developpement, Seuil, Paris.

Todd, E. (1990), L’Invention de l'Europe, Seuil, Paris.

Tur-Prats, A. (2015), Family Types and Intimate-Partner Violence: A Historical Perspective, Barcelona GSE Working Paper No. 835.

Viazzo, P. P. (2003), What's so Special about the Mediterranean? Thirty Years of Research on Household and Family in Italy, Continuity and Change 18, 111-137.

Voigtlander, N. and H.-J. Voth (2013), How the West 'Invented' Fertility Restriction, American Economic Review 103, 2227-2264.

\section{APPENDIX}

Table A1. Summary statistics

\begin{tabular}{|c|c|c|c|c|c|}
\hline Variable & Obs & Mean & Std. Dev. & Min & Max \\
\hline Female mean age at marriage & 69 & 24.694 & 0.989 & $\begin{array}{c}22.112 \\
\text { Girgenti }\end{array}$ & $\begin{array}{l}27.769 \\
\text { Ascoli } \\
\text { Piceno }\end{array}$ \\
\hline Share of brides aged 20 or less & 69 & 14.934 & 7.668 & $\begin{array}{c}2.765 \\
\text { Macerata }\end{array}$ & $\begin{array}{c}40.032 \\
\text { Girgenti }\end{array}$ \\
\hline Female celibacy over 50 & 69 & 10.982 & 3.044 & $\begin{array}{c}4.288 \\
\text { Rovigo }\end{array}$ & $\begin{array}{c}17.413 \\
\text { Napoli } \\
17.6\end{array}$ \\
\hline Illegitimacy rate & 69 & 7.183 & 3.850 & $\begin{array}{c}1.5 \\
\text { Treviso }\end{array}$ & $\begin{array}{l}17.6 \\
\text { Pesaro- } \\
\text { Urbino }\end{array}$ \\
\hline Nuclear family & 69 & 0.536 & 0.502 & 0 & 1 \\
\hline Egalitarian nuclear family with early marriage & 69 & 0.304 & 0.464 & 0 & 1 \\
\hline Egalitarian nuclear family with late marriage & 69 & 0.232 & 0.425 & 0 & 1 \\
\hline Incomplete stem family & 69 & 0.130 & 0.339 & 0 & 1 \\
\hline Communitarian family & 69 & 0.333 & 0.475 & 0 & 1 \\
\hline
\end{tabular}




\section{Description of variables}

A) Family structure data

Female mean age at marriage: We collect data from MAIC (1872, vol. 2) on the age of all brides who got married in 1871. Data are available by age group as follows: below 20, 20-24, 25-29, 3044, 45-59, and over 60 .

Share of brides aged 20 or less: We compute the percentage of brides aged 20 or less over the total number of marriages in 1871. Data are from MAIC (1872, vol. 2).

Female celibacy rate (over age 50): Census 1871 provides detailed information on the marital status of the population disaggregated by gender and by year of age. For each province, we collect data on the age-specific marital status and calculate our indicator as the number of female celibates aged 50 or more over the total number of women in the same age range. The source is MAIC (1872, vol. 2).

Illegitimacy rate: This indicator is calculated from life statistics in 1871 (MAIC, 1874). Births are disaggregated into legitimate, illegitimate, and "esposti" (i.e. abandoned infants). In this work the illegitimacy rate is calculated taking into account both out-of-wedlock births and abandoned infants over the total number of births in the same year. For Rome (and Comarca) data refers to 1872 (MAIC, 1875).

Nuclearity: We define a dummy variable taking value 1 if the province was dominated by nuclear residential habits, 0 if by complex ones. Information is from Todd (1990).

Family types: These variables are taken from Bertocchi and Bozzano (2015), who adapt the classification proposed by Todd (1990) to the Italian specific regional differentiation following Hajnal (1982), Barbagli (1987), and Del Panta et al. (1996). Provinces are coded according to a set of four dummies, one for each family type, i.e. egalitarian nuclear with late marriage, incomplete stem, communitarian, and egalitarian nuclear family with early marriage.

B) 1871 and 1881 data

Height: Since historical data about income or wealth for Italian provinces are not available, we employ height as a proxy. Data on height refer to the mean height of military conscripts aged 20 at the provincial level and are taken from A'Hearn et al. (2011, Table S3). We employ data referring to 1871 and 1881 .

Industrialization: Data on industrialization at the provincial level are taken from Ciccarelli and Fenoaltea (2013, Table 2). The variable is a provincial index of relative industrialization calculated on the basis of census data as the share of industrial value added, excluding construction, over the share of the male population over age 15. We employ data referring to 1871 and 1881 . 
Human capital: We collect data on literacy, female literacy, and male literacy for population aged 20 or more, both for 1871 and 1881, from the censuses (MAIC, 1872, 1883). We also obtain a measure of equality in human capital accumulation as the female to male ratio of literacy rates in both years: this measure ranges between 0 (perfect inequality) to 1 (perfect equality) and is therefore increasing in gender equality.

Crude birth rate: Our fertility measure is the standard one. We collect data on total births in 1871 and 1881 for each province and we calculate the crude birth rate as the number of live births (legitimates, illegitimate, and "esposti") per 1000 inhabitants. The source is MAIC (1874, 1882; for Rome, MAIC, 1875).

C) 2001 data

Income: We use the natural logarithm of total value added per capita in 2001 (Italian lira, constant prices, base year 2000). The source is Istituto Tagliacarne (2011).

Labor market variables: We employ two variables taken from Bozzano (2016). The first refers to the female to male ratio of the labor force participation rate, defined as female labor force participation rate over male labor force participation rate. The second is female to male ratio in economic leadership, defined as the share of women who are in charge of enterprises or in top managerial positions over the share of men employed in the same positions. Both variables are elaborated from the 2001 census and take values between 0 (perfect inequality between women and men) and 1 (perfect equality), so that they increase in gender equality.

Education variables: We employ variables taken from Bertocchi and Bozzano (2015), who collected data on female and male secondary and tertiary attainment for 2001 from the national census (ISTAT, 2009) and computed female to male ratios. Both variables are weighted by female and male population aged 19 or more. The first variable is defined as the ratio between females with at least a high-school diploma over female population over age 19 and males with at least a highschool diploma over male population over age 19. Analogously, the second variable is the ratio between females with a university degree over female population over age 19 and males with a university degree over male population over age 19 .

Fertility rate: This variable is defined as the average number of children per women aged 15-49 (i.e. total fertility rate net of immigration fertility rate) and measured in 2001 (ISTAT, 2009). 